\title{
Soft Soil Foundation Settlement Prediction and Economic Cost Management Analysis based on New Algorithm
}

\author{
Shun Zhou ${ }^{1}$ and Xiao Guang Yue ${ }^{2, *}$ \\ ${ }^{1}$ School of Economics, Wuhan University of Technology, Wuhan 430070, China \\ ${ }^{2}$ School of Resources and Environmental Engineering, Wuhan University of Technology, Wuhan \\ 430070, China \\ *email:xgyue@live.com
}

Keywords: Contrary degree; Opposite Degree; Soft soil; Foundation settlement; Economic cost management.

\begin{abstract}
In order to predict the soft soil foundation settlement and analyze economic cost management, the basic concepts of soil foundation settlement are discussed. A new prediction algorithm is proposed. The new prediction algorithm principles of numerical prediction are described based on the basic concept of contrary degree and Opposite Degree. Firstly, the relevant data is selected from engineering example; then, according to the contrary degree algorithm, the test set and prediction set are calculated based on Opposite Degree computation; finally, in order to evaluation experimental results, the prediction results compared with BP neural network algorithm and Opposite Degree algorithm. The results show that, Opposite Degree computation algorithm is an effective method for settlement prediction of soft soil foundation. At last, we analyzed the economic cost in soft soil foundation and put forward some management suggestions.
\end{abstract}

\section{Introduction}

Soft soil foundation settlement is an important research in geotechnical engineering problem which has aroused widespread attention in its practices. Usually, the soft soil has the following prominent features [1]: 1) High porosity; 2) High water content; 3) Low permeability; 4) High compressibility; 5) Low shear strength; 6) Thix otropy. Foundation is a kind of soil or rock which withstands partial loads from the building. If buildings or structures were built in soft soil environment, the foundations of buildings or structures are called soft settlement [2]. Types, status and environment of soft soil can affect the settlement of soft soil foundation. Soft soil foundation settlement analysis method is mainly divided into two kinds of the following [3]: 1) Theoretical formula method; 2) Numerical analysis method.

To solve the problem of settlement prediction of soft soil foundation, people used many methods, such as: BP neural network and SVM. In 1986, Rumelhart, Williams, Hinton et al proposed BP neural network [4, 5]. Support vector regression is proposed by Vapnik et al [6]. The problem of these methods is the computational process is more complicated; and the results may not be reproduced. We want to propose a new method based on contrary degree for Chinese natural language processing. The concept of contrary degree was proposed by scholars like Fanjin Mai and Ting Wang [7]; it has a good application of natural language processing in the calculation between words. We propose a new prediction algorithm through using different calculation methods based on concept of contrary degree. The main purpose of the algorithm is to make the data stabilize at a similar extent by offsetting positive and negative values, so as to achieve the highest degree of approximation between the data.

\section{Algorithm Descriptions}

Basic Concept. To indicate the known data and predict the extent of the difference between the data, define the degree of approximation, data ranges from infinity to infinitesimal. Generally, defined A as the proximity, $\mathrm{X}$ as the known data, $\mathrm{Y}$ as the prediction data, we got: 


$$
A=\frac{Y-X}{X}
$$

A is more closed to $+\infty, \mathrm{Y}$ is more greater. Greater difference will be showed between $\mathrm{Y}$ and $\mathrm{X}$. A is more closed to $-\infty, \mathrm{Y}$ is more smaller and the bigger difference will be obtained between $\mathrm{Y}$ and $\mathrm{X}$. A more tends to $0, \mathrm{Y}$ more tends to $\mathrm{X}$. When $\mathrm{A}$ equal to $0, \mathrm{X}$ equal to $\mathrm{Y}$.

Numerical prediction calculation. Define a matrix of known data as $X_{m \times n}, \mathrm{R}$ as the corresponding known values. Define a matrix of prediction data, $\mathrm{S}$ as the corresponding prediction values.

Algorithms can be predicted by the matrix operation, the specific steps are as follows:

(1) The proximity of each row of known data matrix $X_{m \times n}$ were calculated, and returned the absolute value of the minimum.

$A(k)$ means the k row's data of $Y_{p \times n}$ were calculated the proximity with every row's data of $X_{m \times n}$.The absolute value of the minimum value was obtained. (If there were two or more the same value, then returned the first value)

$$
A(k)=\min \left\{\begin{array}{l}
\left|\sum_{j=1}^{n} \frac{y_{k j}-x_{1 j}}{x_{1 j}}\right| \\
\left|\sum_{j=1}^{n} \frac{y_{k j}-x_{i j}}{x_{i j}}\right|
\end{array}\right.
$$

(2) Return $A(k)$ to ${ }^{r_{i}}$ of corresponding R. ${ }^{r_{i}}$ is the closed data of the ${ }^{k}$ row of $Y_{p \times n}$.

(3) Calculated according to the formula, we can get ${ }^{s_{p}}$ of $S$.

$$
\frac{s_{p}-r_{i}}{r_{i}}=A^{\prime}(k)
$$

$A^{\prime}(k)$ is the true value of $A(k)$, not the absolute value of $A(k)$.

(4) Repeat (1), (2) and (3), until all of the ${ }^{s_{p}}$ were calculated. ${ }^{s_{p}}$ build up matrix $S$.

(5) Output the result.

\section{Calculation Process}

Data Source. Embankment settlement observation data of Lianxu highway K14+116 section [8], for example, as shown in Table 1.Considing the data of the original data and the time interval in the observation make a weaker contribution to the forecast. Then, select part of the data (total filling time, total filing height, and total settlement amount) as test projects.

Table 1 Experimental Data

\begin{tabular}{cccc}
\hline NO. & Total filing time $(\mathrm{mm})$ & Total filing height $(\mathrm{mm})$ & Total settlement amount $(\mathrm{mm})$ \\
\hline 1 & 0 & 0 & 0 \\
2 & 29 & 3.03 & 8 \\
3 & 60 & 3.21 & 69 \\
4 & 91 & 3.41 & 90 \\
5 & 122 & 3.41 & 90 \\
6 & 153 & 3.57 & 109 \\
7 & 184 & 3.90 & 122 \\
8 & 215 & 3.90 & 126 \\
9 & 246 & 3.90 & 134 \\
10 & 277 & 3.90 & 134
\end{tabular}




\begin{tabular}{llll}
11 & 308 & 3.90 & 134 \\
12 & 339 & 3.90 & 134 \\
13 & 370 & 3.90 & 140 \\
14 & 401 & 3.90 & 144 \\
15 & 432 & 3.90 & 144 \\
16 & 463 & 4.20 & 144 \\
17 & 494 & 4.80 & 156 \\
18 & 525 & 5.60 & 158 \\
19 & 556 & 5.87 & 163 \\
20 & 587 & 5.87 & 176 \\
21 & 618 & 5.87 & 187 \\
22 & 649 & 5.87 & 198 \\
23 & 680 & 5.87 & 205 \\
24 & 711 & 5.87 & 205 \\
25 & 742 & 5.87 & 208 \\
\hline
\end{tabular}

(1) Select the training set and test set. First import the data which are in the front of the table. Select the total filing time and total filing height of the import data as the first test matrix of training set. The row data of the later test matrix are the corresponding total settlement amount.

(2) Calculate the proximity. The result is shown in table 2.

(3) Calculate the later test matrix (total settlement amount). The results are shown in Table 3 . In order to compare the experimental results, using the Matlab simulation, creating and training the BP neural network model (the maximum number of training is 1000 , the network performance objectives is 0.001 , learning rate is 0.1 ), the results shown in Figure 1 ( $\mathrm{PV}$ is prediction value, TV is true value).

Table 2 The Opposite Degree computation of the results

\begin{tabular}{cccccc}
\hline NO. & OD & OD & OD & OD & OD \\
\hline 1 & $/$ & $/$ & $/$ & $/$ & $/$ \\
2 & 21.2476 & 22.3166 & 23.3856 & 24.4545 & 25.5235 \\
3 & 10.1287 & 10.6453 & 11.162 & 11.6787 & 12.1953 \\
4 & 6.51262 & 6.85328 & 7.19394 & 7.53459 & 7.87525 \\
5 & 4.78698 & 5.04108 & 5.29518 & 5.54928 & 5.80337 \\
6 & 3.68347 & 3.88609 & 4.0887 & 4.29132 & 4.49393 \\
7 & 2.86382 & 3.0323 & 3.20078 & 3.36926 & 3.53774 \\
8 & 2.37955 & 2.52373 & 2.66792 & 2.8121 & 2.95629 \\
9 & 2.01732 & 2.14334 & 2.26936 & 2.39537 & 2.52139 \\
10 & 1.73618 & 1.84809 & 1.96 & 2.07192 & 2.18383 \\
11 & 1.51162 & 1.61227 & 1.71292 & 1.81357 & 1.91422 \\
12 & 1.32814 & 1.41958 & 1.51103 & 1.60247 & 1.69392 \\
13 & 1.1754 & 1.25918 & 1.34297 & 1.42675 & 1.51053 \\
14 & 1.04628 & 1.12358 & 1.20089 & 1.2782 & 1.3555 \\
15 & 0.93568 & 1.00744 & 1.0792 & 1.15096 & 1.22272 \\
16 & 0.73239 & 0.79935 & 0.8663 & 0.93326 & 1.00021 \\
17 & 0.47393 & 0.53668 & 0.59943 & 0.66219 & 0.72494 \\
18 & 0.22536 & 0.2844 & 0.34345 & 0.4025 & 0.46155 \\
19 & 0.11151 & 0.16727 & 0.22302 & 0.27878 & 0.33453 \\
20 & 0.05281 & 0.10562 & 0.15843 & 0.21124 & 0.26405 \\
\hline
\end{tabular}




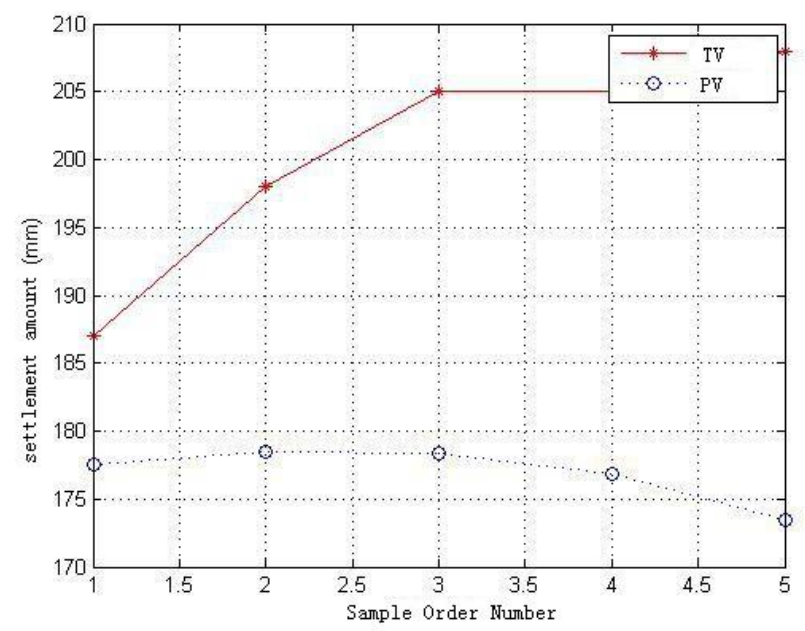

Figure. 1 The prediction results by using BP neural network

Table 3 Total settlement amount by using OD

\begin{tabular}{cccc}
\hline NO. & $\begin{array}{c}\text { Total } \\
\text { settlement } \\
\text { amount }(\mathrm{mm})\end{array}$ & \multicolumn{2}{c}{$\begin{array}{c}\text { Total settlement amount by } \\
\text { using OD }\end{array}$} \\
\cline { 3 - 4 } & 187 & 185.29456 & 0.00912 \\
& results $(\mathrm{mm})$ & errors \\
\hline 1 & 198 & 194.58912 & 0.01723 \\
3 & 205 & 203.88368 & 0.01723 \\
4 & 205 & 213.17824 & 0.03990 \\
5 & 208 & 222.4728 & 0.06958 \\
\hline
\end{tabular}

Table 4 Total settlement amount by using BP

\begin{tabular}{|c|c|c|c|}
\hline \multirow[t]{2}{*}{ NO. } & \multirow{2}{*}{$\begin{array}{c}\text { Total } \\
\text { settlement } \\
\text { amount }(\mathrm{mm})\end{array}$} & \multicolumn{2}{|c|}{$\begin{array}{c}\text { Total settlement amount by } \\
\text { using BP }\end{array}$} \\
\hline & & results $(\mathrm{mm})$ & errors \\
\hline 1 & 187 & 177.5958 & 0.05029 \\
\hline 2 & 198 & 178.5231 & 0.09837 \\
\hline 3 & 205 & 178.3621 & 0.12994 \\
\hline 4 & 205 & 176.8482 & 0.13733 \\
\hline 5 & 208 & 173.4462 & 0.16612 \\
\hline \multicolumn{4}{|c|}{ Table 5 Everage Error of OD } \\
\hline NO. & $\begin{array}{c}\text { Total } \\
\text { settlement } \\
\text { amount }(\mathrm{mm})\end{array}$ & \multicolumn{2}{|c|}{ Everage Error of OD } \\
\hline 1 & 187 & \multirow{5}{*}{\multicolumn{2}{|c|}{0.030612}} \\
\hline 2 & 198 & & \\
\hline 3 & 205 & & \\
\hline 4 & 205 & & \\
\hline 5 & 208 & & \\
\hline
\end{tabular}


Table 6 Everage Error of BP

\begin{tabular}{ccc}
\hline NO. & $\begin{array}{c}\text { Total } \\
\text { settlement } \\
\text { amount }(\mathrm{mm})\end{array}$ & Everage Error of BP \\
\hline 1 & 187 & \\
2 & 198 & 0.11641 \\
3 & 205 & \\
4 & 205 & \\
5 & 208 & \\
\hline
\end{tabular}

We can draw the following conclusions from Table 3 and 4 and 5 and 6, the average error of new algorithm is 0.030612 , and the average error of BP neural network is 0.11641 . The average prediction error of new algorithm is significantly smaller than the BP neural network method. Data from each result, the new algorithm prediction error accuracy of the data are controlled at a better level.

\section{Conclusion}

In order to predict and analyze settlement of soft soil, specifically introduce the basic concepts of soft soil and the foundation. A new algorithm based on the degree of approximation with the reference to contrary degree is proposed. By selecting the actual data, and through simulation, the opposite degree algorithm is an effective prediction method and has an obviously superior in predicting compared BP neural network. The research provides a new idea for prediction of foundation settlement and has some theoretical significance and application value of engineering. For the soft soil foundation economic cost management, We need to strengthen the management of the sense of responsibility and professional quality; the daily accounting and supervision work is also very important; we need to do a good job of predicting the monitoring of the material management work, and focus on early warning for executing contract and cost management.

\section{Acknowledgement}

This study was financially supported by International Cooperation Project from Wuhan Science and Technology Bureau (No. 2013030409020108) and Self-determined and Innovative Research Funds of WUT (2014-JL-007).

\section{References}

[1] Jianjun Shen, the Study about Combination Prediction of Soft Foundation Settlement, Shandong University, Jinan, China, 2010 (in Chinese).

[2] Yi Chang, The Study about Prediction of Soft Foundation Settlement at Guangzhou Nansha, Central South University, Changsha, China 2007 (in Chinese).

[3] Zhao Shitao. The Study on the Settlement of Road Soft Soil Foundation by Variable-weight Combianation Forecasting Model [D]. Harbin: Northeast Forestry University, 2007 (in Chinese).

[4] Rumelhart, D. E., Hinton, G. E., \&Williams, R. J. (1986a). Learning internal representations by error propagation. In (Rumelhart et al., 1986b), Chap. 8, pp. 318-362.

[5] Rumelhart, D. E., McClelland, J. L.,\&PDP Research Group (Eds.). (1986b). Parallel distributed processing. volume 1: Foundations. Cambridge, MA: MIT Press.

[6] Vapnik V. The Nature of Statistical Learning Theory [M]. New York: Springer-Verlag, 1995.

[7] MAI Fan-jin, WANG Ting, SONG Rui. A Model of the Contrary Degree among Different Semantic Meanings [C]// Proceedings of the 7th International Conference on Chinese Computing. Beijing, China, PHEI, 2007: 204-209.

[8] Wei Feng, The application of MATLAB-ANN System in Prediction of Soft Foundation Settlement of Highway, Chang'an University, Xi'an, China, 2005 (in Chinese). 